\title{
Post-mRNA COVID-19 Vaccination Myocarditis
}

\author{
Abhishek Matta ${ }^{1,2}$, Rekha Kallamadi ${ }^{1,2}$, Danielle Matta ${ }^{2}$, Dinesh Bande ${ }^{1,2}$ \\ ${ }^{1}$ University of North Dakota School of Medicine and Health Sciences, Grand Forks, USA \\ ${ }^{2}$ Sanford Health, Fargo, USA
}

Received: $12 / 07 / 2021$

Accepted: $12 / 07 / 2021$

Published: 16/08/2021

How to cite this article: Matta A, Kallamadi R, Matta D, Bande D. Post-mRNA COVID-19 vaccination myocarditis. EJCRIM 2021;8:

doi:10.12890/2021_002769.

Conflicts of Interests: The authors declare there are no competing interests.

This article is licensed under a Commons Attribution Non-Commercial 4.0 License

\section{ABSTRACT}

A new trend of myocarditis among young adults who received mRNA vaccines for COVID-19 is emerging. We present the case of a young adult who presented with chest pain 3 days after the second dose of Pfizer-BioNTech COVID-19 vaccine. He had elevated troponin I and C-reactive protein levels at the time of admission. Electrocardiogram (ECG) and echocardiogram findings were unremarkable. The patient improved with conservative management and was discharged home the next day.

\section{LEARNING POINTS}

- Myocarditis is rare but is increasingly being reported in young adults post vaccination for COVID-19.

- Patients usually present with chest pain, elevated troponin and/or inflammatory markers.

- The condition carries a good prognosis and patients usually recover with supportive care.

\section{KEYWORDS}

COVID-19, myocarditis, COVID-19 vaccine

\section{CASE DESCRIPTION}

A 27-year-old male presented to our emergency room with sharp, central, non-radiating chest pain associated with fatigue, 3 days after his second dose of Pfizer-BioNTech COVID-19 vaccine. The patient did not report any fever, chills, diaphoresis, upper or lower respiratory tract infection symptoms, nausea, vomiting or diarrhoea. He did not have any history of acute COVID-19 infection. Vitals were within normal limits. The physical examination was unremarkable. The ECG showed normal sinus rhythm without any ST-T changes. Chest $\mathrm{x}$-ray showed no acute cardiopulmonary process. The patient was given aspirin $325 \mathrm{mg}$ oral once and the symptoms resolved.

Laboratory data showed elevated troponin I $(0.245 \mathrm{ng} / \mathrm{ml}$, normal 0-0.028 ng/ml) and C-reactive protein (44.2 mg/l, normal 0.0-8.0 mg/l) (Table 1).

Troponin I peaked $(0.391 \mathrm{ng} / \mathrm{ml}) 6$ hours after the initial troponin. The echocardiogram showed a normal ejection fraction of $60 \%$ and no regional wall motion changes or pericardial effusion. The patient was monitored overnight in the hospital. Telemetry showed no arrythmias. The patient was discharged home the next day.

\section{DISCUSSION}

A new trend of myocarditis among young adults who received mRNA vaccines for COVID-19 is emerging ${ }^{[1]}$. According to the Centers for Disease Control and Prevention (CDC) Vaccine Adverse Event Reporting System (VAERS), as of June 19th 2021, there have been 1,068 cases of myocarditis reported after administration of various vaccines since $1991^{[1,2]}$. Out of these, 778 cases of myocarditis have been 


\begin{tabular}{|c|c|c|}
\hline Laboratory test & Value & Reference range \\
\hline Troponin I & 0.245 & $0-0.028 \mathrm{ng} / \mathrm{ml}$ \\
\hline WBC & 10 & $4-11 K / \mu l$ \\
\hline$H b$ & 15 & $13.5-17.5 \mathrm{~g} / \mathrm{dl}$ \\
\hline Platelets & 127 & $140-400 \mathrm{~K} / \mu \mathrm{l}$ \\
\hline Total bilirubin & 2.0 & $0.2-1.2 \mathrm{mg} / \mathrm{dl}$ \\
\hline Direct bilirubin & 0.7 & $0-0.4 \mathrm{mg} / \mathrm{dl}$ \\
\hline Alanine aminotransferase (ALT) & 18 & $0-55 \mathrm{U} / \mathrm{I}$ \\
\hline $\begin{array}{c}\text { Aspartate aminotransferase } \\
\text { (AST) }\end{array}$ & 23 & $0-35 \mathrm{U} / \mathrm{I}$ \\
\hline Alkaline phosphatase & 62 & $30-150 \mathrm{U} / \mathrm{I}$ \\
\hline C-reactive protein (CRP) & 44.2 & $0.0-8.0 \mathrm{mg} / \mathrm{l}$ \\
\hline ESR & 7 & $0-14 \mathrm{~mm} / \mathrm{hr}$ \\
\hline D-dimer & $<0.27$ & $<0.49 \mu \mathrm{g} / \mathrm{ml}$ \\
\hline ANA screen & Negative & Negative \\
\hline
\end{tabular}

reported post COVID-19 vaccination (predominantly Pfizer-BioNTech and Moderna) which constitutes 72.9\% of all reported cases [2]. Cases of myocarditis have also been reported post vaccination for smallpox (20.3\%), anthrax (5.9\%), influenza (4.9\%), typhoid (2.7\%) and hepatitis B (2.4\%) ${ }^{[2]}$. The initial reports of the condition came from the Times of Israel which reported 62 cases of myocarditis post PfizerBioNTech vaccination in Israel ${ }^{[3]}$. Cases of myocarditis following vaccination have been reported from the US military as well ${ }^{[4]}$. Initial case reports in the medical literature were reported from Europe ${ }^{[5,6]}$. A case series of 7 cases was reported from the USA ${ }^{[7]}$ and 6 cases were reported later from Israel ${ }^{[8]}$.

The first case of myocarditis post COVID-19 vaccination in the medical literature was reported in a 39-year-old from Europe and he made a good recovery with anti-inflammatory treatment ${ }^{[5]}$. Ammirati et al. reported a case of myocarditis in a 59-year-old patient who presented after his second vaccination dose with chest pain, elevated C-reactive protein and troponin and made a spontaneous recovery ${ }^{[6]}$.

The 7 cases reported by Marshall et al. were aged between 14-19 years old ${ }^{[7]}$. All of these had elevated troponin. Six patients received nonsteroidal anti-inflammatory drugs (NSAIDs) and 4 were treated with steroids and IVIG [7]. All of them made a good recovery [7].

Abu Mouch et al. ${ }^{[8]}$ reported 6 cases aged between $16-45$ years. All of these had elevated C-reactive protein and troponin levels as well ${ }^{[8]}$. All of them were treated with NSAIDs and colchicine and made a good recovery ${ }^{[8]}$.

The literature shows that post-vaccination myocarditis seems to be reported more in young adults, within 2-4 days of vaccination and that most patients improve with conservative management ${ }^{[7,8]}$. Identifying the condition promptly is necessary as we can avoid unnecessary and expensive investigation in these patients. A causal association between the mRNA vaccines and myocarditis is unknown. Its pathophysiology is currently undetermined and needs to be further investigated.

Our patient was a young male who had symptoms within 3 days after his second vaccination dose. The elevated troponin I and C-reactive protein levels suggested ongoing myocarditis. Our patient did not have any symptoms suggestive of an ongoing viral infection. The diagnosis of post-COVID-19 vaccination myocarditis was made based on his medical history, the temporal association with vaccination, laboratory data and medical literature review. Since he recovered in a short time, we did not pursue any further expensive investigations. 


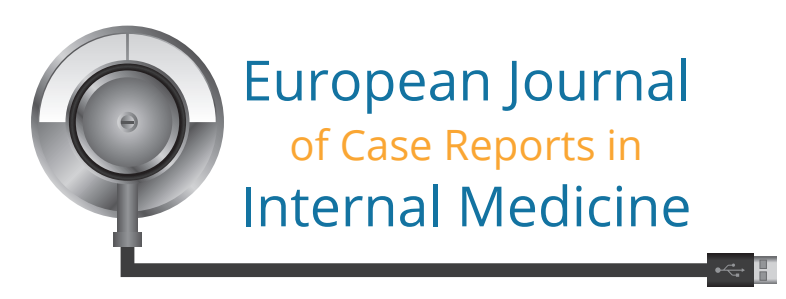

\section{REFERENCES}

1. Centers for Disease Control and Prevention (CDC) [Internet]. Clinical considerations: myocarditis after mRNA COVID-19 vaccines. Available from: https://www.cdc.gov/ vaccines/covid-19/clinical-considerations/myocarditis.html (accessed 03 June 2021).

2. Centers for Disease Control and Prevention (CDC) [Internet]. The Vaccine Adverse Event Reporting System (VAERS) Results Form. Available from: https://wonder.cdc.gov/ controller/datarequest/D8; jsessionid=9F95016CF66DC479F6CF241B9360 (accessed 18 June 2021).

3. The Times of Israel [Internet]. Israel said probing link between Pfizer shot and heart problem in men under 30. Available from: https://www.timesofisrael.com/israel-saidprobing-link-between-pfizer-shot-and-heart-problem-in-men-under-30/ (accessed 03 June 2021).

4. Military.com [Internet]. Pentagon tracking 14 cases of heart inflammation in troops after COVID-19 shots. Available from: https://www.military.com/daily-news/2021/04/26/ pentagon-tracking-14-cases-of-heart-inflammation-troops-after-covid-19-shots.html (accessed 03 June 2021).

5. Bautista García J, Peña Ortega P, Bonilla Fernández JA, Cárdenes León A, Ramírez Burgos L, Caballero Dorta E. [Acute myocarditis after administration of the BNT162b2 vaccine against COVID-19]. Rev Esp Cardiol. Epub 2021 Mar 20. doi: 10.1016/j.recesp.2021.03.009.

6. Ammirati E, Cavalotti C, Milazzo A, Pedrotti P, Soriano F, Schroeder JW, et al. Temporal relation between second dose BNT162b2 mRNA Covid-19 vaccine and cardiac involvement in a patient with previous SARS-COV-2 infection. Int J Cardiol Heart Vasc 2021;34:100774.

7. Marshall M, Ferguson ID, Lewis P, Jaggi P, Gagliardo C, Collins JS, et al. Symptomatic acute myocarditis in seven adolescents following Pfizer-BioNTech COVID-19 vaccination Pediatrics. Epub 2021 Jun 4. doi: 10.1542/peds.2021-052478.

8. Abu Mouch S, Roguin A, Hellou E, Ishai A, Shoshan U, Mahamid L, et al. Myocarditis following COVID-19 mRNA vaccination. Vaccine 2021;39:3790-3793. 